\title{
Multidrug-resistant organisms detected in refugee patients admitted to a University Hospital, Germany June-December 2015
}

C Reinheimer ${ }^{1}$, VAJ Kempf ${ }^{1}$, S Göttig ${ }^{1}$, M Hogardt $^{1}$, TA Wichelhaus ${ }^{1}$, F 0’Rourke ${ }^{1}$, C Brandt $^{1}$

1. Institute for Medical Microbiology and Infection Control, University Hospital Frankfurt am Main, Germany

Correspondence: Volkhard A. J. Kempf (volkhard.kempf@kgu.de)

Citation style for this article:

Reinheimer C, Kempf V, Göttig S, Hogardt M, Wichelhaus T, O’Rourke F, Brandt C. Multidrug-resistant organisms detected in refugee patients admitted to a University Hospital, Germany June-December 2015. Euro Surveill. 2016;21(2):pii=30110. DOI: http://dx.doi.org/10.2807/1560-7917.ES.2016.21.2.30110

Article submitted on 23 December 2015 / accepted on 14 January 2016 / published on 14 January 2016

Multidrug-resistant Gram-negative bacteria (MDR GNB) were found to colonise $60.8 \%$ ( $95 \%$ confidence interval: 52.3-68.9) of 143 refugee patients mainly from Syria (47), Afghanistan (29), and Somalia (14) admitted to the University Hospital Frankfurt, Germany, between June and December 2015. This percentage exceeds the prevalence of MDR GNB in resident patients four-fold. Healthcare personnel should be aware of this and the need to implement or adapt adequate infection control measures.

Current data provided by Federal Agency of Migration and Refugees, Germany, indicate a dramatic increase in migration, with most people arriving from Syria, Albania, Afghanistan and Iraq [1]. These countries are known as countries with high prevalence for multidrug-resistant Gram-negative bacteria (MDR GNB) (Enterobacteriaceae, Acinetobacter baumannii) and for meticillin-resistant Staphylococcus aureus (MRSA) [2-5]. People from these countries are thus at higher risk of being colonised with such pathogens and adequate infection prevention measures need to be taken to prevent spread in healthcare settings in the countries where they seek refuge. Systematic studies regarding prevalence of multidrug-resistant organisms (MDRO) in refugees are not yet available in the scientific literature. In order to fill this gap, we investigated the prevalence of MDR GNB and MRSA in patients admitted from refugee (REF) accommodations to the University Hospital Frankfurt am Main (UHF), Germany between June and December 2015 and compared it with prevalence in resident patients. Investigation of prevalence of multidrug-
resistant organisms in refugee and resident
patients
At UHF, all patients admitted from hospitals in countries with high prevalence or from refugee accommodations are pre-emptively isolated and screened for MDRO on the day of admission. The same algorithm is applied to resident patients with previous treatment in hospitals in countries with high prevalence for MDRO and all patients admitted to intensive/intermediate care units (ICUs/IMCs).

During the study period, REF patients were identified on admission and screened for MDRO by rectal swabs for MDR GNB and nasal swabs for MRSA. MDR GNB screening was undertaken for extended spectrum beta-lactamase (ESBL)-producing Enterobacteriaceae, and Enterobacteriaceae and Acinetobacter baumannii resistant to piperacillin, any third generation cephalosporin, and fluoroquinolones +/- carbapenems.

Patients admitted to ICU/IMC within the same period were included as comparison group since these patients are routinely screened for MDRO. This group reflects the demographic and epidemiological characteristics of the resident population not admitted from a refugee accommodation (NREF).

Patients admitted from hospitals in countries with high prevalence for MDRO were excluded from the study.

MDRO screening was done in accordance to German infection protection law and the infection control strategy at UHF. Ethical approval was given by Ethics Committee of the UHF.

\section{Laboratory identification of multidrug- resistant bacteria}

For detection of MDR GNB, rectal swabs were collected using Amies collection and transport medium (Hain Lifescience, Germany) and streaked onto CHROMagarTM ESBL plates (Mast Diagnostica, Paris, France). Identification of MDR GNB species was done by matrix-assisted laser desorption/ionisation time-offlight (MALDI-TOF) mass spectrometry. Antimicrobial susceptibility testing was performed using VITEK2 (bioMérieux, Nürtingen, Germany) according to Clinical 
Countries of origin of refugees screened for multidrug-resistant Gram-negative bacteria and meticillin resistant Staphylococcus aureus, Frankfurt, Germany June-October 2015 ( $\mathrm{n}=143$ )

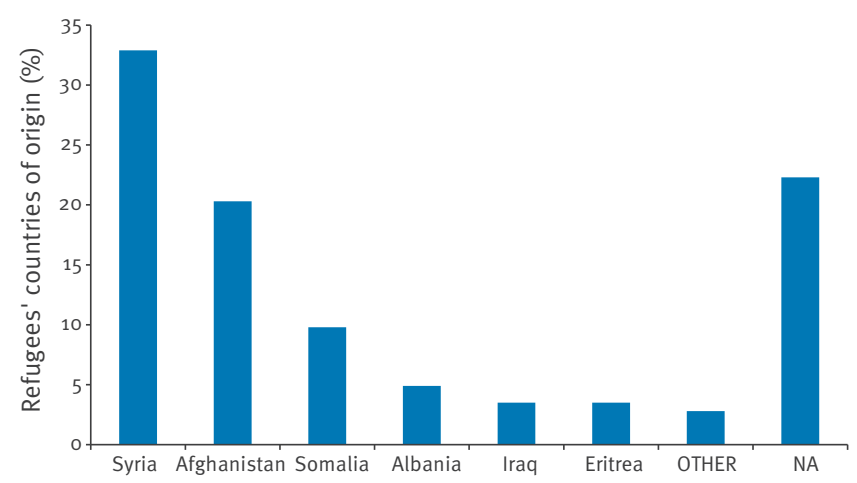

OTHER are Pakistan, Moldavia, Lebanon, or Georgia. NA: information about country of origin not available.

and Laboratory Standards Institute (CLSI) guidelines [Version M100-S25, 2015] and antibiotic gradient tests (bioMérieux).

Carbapenemase-encoding genes were detected via PCR analysis and subsequent sequencing from carbapenem-resistant Enterobacteriaceae including the bla genes for carbapenemases NDM, VIM, IMP, OXA-48, and KPC and OXA-23, OXA-24, OXA-51, and OXA58 for $A$. baumannii $[6,7]$. Carbapenem-resistant $A$. baumannii isolates were assigned to international clusters by repetitive element sequence based-PCR (DiversiLab ${ }^{\circledR}$, bioMérieux) $[7,8]$.

For the detection of MRSA, moistened nasal swabs were inoculated on Brilliance MRSA Agar (Oxoid, Wesel, Germany) and identification and antimicrobial susceptibility testing were performed as described above. Clonal identity was determined by staphylococcal protein $A$ (spa) typing using the Ridom StaphType software (Ridom GmbH, Würzburg, Germany) [9].

We used the biostatistical data file from University Münster, Germany for statistical analyses [10]. Confidence intervals $(\mathrm{Cl})$ were calculated based on binomial distribution and $p$ values (2-tailed) of $p \leq 0.05$ were considered statistically significant.

\section{Prevalence in refugee compared with resident patients}

Multidrug-resistant Gram-negative bacteria

Between June and December 2015, a total of 143 REF and 1,489 NREF were screened for MDR GNB on day of admission. The average age in the two groups was 21.7 years (range 1-65, SD 16.4) for REF and 64 years (11-94; SD 16.2) for NREF, respectively. Of REF patients $84.6 \%$ were male and of NREF $69.4 \%$. REFs' countries of origin were not available for evaluation in 32 cases (22.4\%) due to lacking records in patients' files (Figure).

Of the 143 REF samples $60.8 \%$ (for $95 \% \mathrm{Cl}$ and patient numbers see Table) were positive for any MDR GNB, significantly exceeding the rate in NREF $(16.7 \%)(p \leq 0.05)$.

Among all MDR GNB species, ESBL-producing Escherichia coli were detected with higher prevalence in REF than in NREF (23.8 vs $4.9 \%$ ). Prevalence of ESBL-producing Klebsiella pneumoniae exceeded the prevalence in NREF (4.2 vs $0.8 \%$ ). Prevalence of ESBLproducing $E$. coli with additional resistance to fluoroquinolones was higher in REF than that in NREF (26.6 vs $6.9 \%$ ) and ESBL-producing K. pneumoniae with additional resistance to fluoroquinolones were found in a higher proportion in REF compared with NREF (4.2 vs $1.9 \%)$. All results were statistically significant.

One REF carried three MDR GNB organisms: ESBLproducing $E$. coli with additional resistance to fluoroquinolones, ESBL-producing $K$. pneumoniae and carbapenem-resistant $A$. baumannii. Two REF were positive for two MDR GNB organisms each; one carried $E$. coli with additional resistance to fluoroquinolones and ESBL-producing $K$. pneumoniae with additional resistance to fluoroquinolones, one carried ESBLresistant $E$. coli and ESBL-resistant $E$. coli with additional resistance to fluoroquinolones.

In REF, three carbapenem-resistant isolates were detected: one carbapenem-resistant $K$. pneumoniae, expressing VIM-1 which is frequently detected in southern Europe [11], and two carbapenem-resistant $A$. baumannii (1.4\%), harbouring carbapenemases OXA-23 and OXA-24, respectively. Strain typing revealed that these isolates belong to international cluster II which is disseminated worldwide and is frequently associated with OXA carbapenemases $[7,8]$.

In NREF, 16 (1.1\%) carbapenem-resistant isolates were detected. Two of these were identified as K. pneumoniae expressing OXA-48, one expressed OXA-48 and $N D M-1$, and in seven isolates no specific carbapenemase gene was detected. Carbapenem-resistant E. coli isolates were detected in three cases with all of them expressing OXA-48. Carbapenem-resistant Enterobacter cloacae strains were detected in two cases with one expressing OXA-48 and one without specific carbapenemase gene detection. Carbapenemresistant $A$. baumannii was detected in one case; no other carbapenemase than species-specific OXA-51 was detectable.

\section{Meticillin-resistant Staphylococcus aureus}

Screening for MRSA was performed for 143 REF and 1,170 NREF. In REF, eight MRSA isolates $(5.6 \%$; $95 \% \mathrm{Cl}$ : 2.5-10.7) were detected, which significantly exceeded the prevalence in NREF where 14 isolates were positive (1.2\%; 95\% Cl: 0.6-2.0). Spa types in REF ( $n=1$ not 
Distribution of multidrug-resistant Gram-negative bacteria in refugee compared with resident patients, Frankfurt, Germany July-December 2015

\begin{tabular}{|c|c|c|c|c|}
\hline & \multicolumn{2}{|c|}{$\begin{array}{l}\text { Patients admitted from refugee accommodations } \\
\text { (REF) }\end{array}$} & \multicolumn{2}{|c|}{$\begin{array}{l}\text { Resident patients not admitted from refugee } \\
\text { accommodation (NREF) }\end{array}$} \\
\hline \multirow[t]{2}{*}{ Total number of patients } & \multicolumn{2}{|c|}{143} & \multicolumn{2}{|c|}{1,489} \\
\hline & $\%(n)$ & $95 \% \mathrm{Cl}$ & $\%(n)$ & $95 \% \mathrm{Cl}$ \\
\hline Positive for MDR GNB ${ }^{a}$ & $60.8(87)$ & $52.3-68.9$ & $16.7(250)$ & $14 \cdot 9-18.8$ \\
\hline Escherichia coli $\mathrm{ESBL}^{\mathrm{b}}$ & $23.8(34)$ & $17.1-31.5$ & $4.9(73)$ & $3.8-6.1$ \\
\hline Escherichia coli $\mathrm{ESBL} / \mathrm{FQ}^{\mathrm{b}}$ & $26.6(38)$ & $19 \cdot 5-34.6$ & $6.9(104)$ & $5 \cdot 7-8.4$ \\
\hline \multirow[b]{2}{*}{ Escherichia coli Carba } & $0.0(0)$ & $0.0-2.5$ & $0.2(3)$ & $0.04-0.5$ \\
\hline & \multicolumn{2}{|c|}{$\begin{array}{c}\text { Carbapenemases } \\
\text { None }\end{array}$} & \multicolumn{2}{|c|}{$\begin{array}{c}\text { Carbapenemases } \\
\text { OXA-48 (3) }\end{array}$} \\
\hline Klebsiella pneumoniae $\mathrm{ESBL}^{\mathrm{b}}$ & $4.2(6)$ & $1.5-8.9$ & $0.8(12)$ & $0.4-1.4$ \\
\hline Klebsiella pneumoniae $\mathrm{ESBL} / \mathrm{FQ}^{\mathrm{b}}$ & $4.2(6)$ & $1.5-8.9$ & $1.9(28)$ & $1.2-2.7$ \\
\hline \multirow[b]{2}{*}{ Klebsiella pneumoniae Carba } & $0.7(1)$ & $0.02-3.8$ & $0.6(10)$ & $0.3-1.2$ \\
\hline & \multicolumn{2}{|c|}{$\begin{array}{l}\text { Carbapenemases } \\
\qquad \text { VIM-1(1) }\end{array}$} & \multicolumn{2}{|c|}{$\begin{array}{c}\text { Carbapenemases } \\
\text { OXA-48 (2) } \\
\text { OXA-48 and NDM-1 (1) } \\
\text { No carbapenemase detected (7) }\end{array}$} \\
\hline Enterobacter cloacae Ceph/FQ & $0.0(0)$ & N.a. & $0.5(8)$ & $0.2-1.1$ \\
\hline \multirow[b]{2}{*}{ Enterobacter cloacae Carba } & $0.0(0)$ & N.a. & $0.1(2)$ & $0.02-0.5$ \\
\hline & \multicolumn{2}{|c|}{$\begin{array}{l}\text { Carbapenemases } \\
\text { None }\end{array}$} & \multicolumn{2}{|c|}{$\begin{array}{c}\text { Carbapenemases } \\
\text { OXA-48 (1) } \\
\text { No carbapenemase detected (1) }\end{array}$} \\
\hline Enterobacter aerogenes Ceph/FQ & $0.0(0)$ & N.a & $0.2(3)$ & $0.04-0.5$ \\
\hline Citrobacter freundii Ceph/FQ & $0.0(0)$ & N.a. & $0.3(4)$ & $0.07-0.7$ \\
\hline Klebsiella oxytoca Ceph/FQ & $0.0(0)$ & N.a. & $0.06(1)$ & $0.002-0.3$ \\
\hline $\begin{array}{l}\text { Acinetobacter baumannii } \\
\text { Ceph/FQ }\end{array}$ & $0.0(0)$ & N.a & $0.06(1)$ & $0.002-0.3$ \\
\hline \multirow[b]{2}{*}{ Acinetobacter baumannii Carba } & $1.4(2)$ & $0.2-0.5$ & $0.06(1)$ & $0.002-0.3$ \\
\hline & \multicolumn{2}{|c|}{$\begin{array}{c}\text { Carbapenemases }{ }^{c} \\
\text { OXA-23 (1) } \\
\text { OXA-24 (1) }\end{array}$} & \multicolumn{2}{|c|}{$\begin{array}{l}\text { Carbapenemases } \\
\text { No carbapenemase detected (1) }\end{array}$} \\
\hline
\end{tabular}

Carba: resistance to carbapenems; ESBL: extended beta-spectrum lactamase-producing; FQ: resistance to fluoroquinolones; MDR GNB: multidrug-resistant Gram-negative bacteria.

a Organism and resistance pattern.

${ }^{b}$ Values in neighboring columns vary statistically significantly $(p \leq 0.05)$.

c Other than species-specific OXA-51.

determined) were t223 $(n=2), t 386, t 790, t 852, t 1532$, and $\mathrm{t} 10343$ ( $\mathrm{n}=1$ each) and spa types in NREF were too3 $(n=8)$, to32 $(n=2)$, too8, to12, to34, and t127 $(n=1$ each).

\section{Discussion and conclusion}

Having protocols in place to control infectious disease transmission in hospitals is good practice to ensure patient safety and should be the focus of preventive efforts. While travel to countries with high prevalence, medical tourism, or contact to local healthcare in such countries have been identified as contributing to the transmission and geographical spread of MDRO worldwide $[2,3,5,12]$, considerations on limiting the spread of MDRO should be expanded to people coming from or passing through countries with high prevalence and seeking refuge, for example in Germany. In terms of hospital infection control strategies, this population may represent a yet unidentified risk in countries with low endemicity.

Our study has revealed a strong link between the status REF and carriage of MDR GNB and MRSA exceeding that of NREF, which might constitute an inherent risk of introduction in another countries healthcare system, such as previously observed in Turkey, where NDM-1-producing $A$. baumannii strains were most likely imported from neighbouring Syria [13]. MRSA spa types detected in REF were less common in Germany whereas NREF colonised with MRSA were found to harbour spa types known to be most frequent in Germany [14].

According to the guidelines by the infection prevention commission (KRINKO) at the Robert-Koch Institute, Berlin, Germany, isolation is recommended for all hospitalised patients for the following patient groups: patients with MRSA [15] and patients with 
carbapenem-resistant MDR GNB [16]. Additionally, in hospital units at high risk for nosocomial transmissions such as ICUs and IMCs, isolation of patients with MDR GNB resistant to cephalosporins and fluoroquinolones and/or MDR GNB with resistance to carbapenems is recommended. In our study the latter would apply to $32.9 \%$ of REF versus $10.9 \%$ of NREF patients. Taking all KRINKO guidelines (including MRSA) into account, a total of $38.5 \%$ of REF and $12.1 \%$ of NREF would qualify for isolation. The demonstrated high MDRO prevalence in our REF study population calls for intensive efforts in hospital hygiene to guarantee best medical practice for every single patient.

While it is hardly possible to predict any evolutionary or geographical success of these MDRO strains in German hospitals or elsewhere in Europe, our small-scale investigation provides some evidence for the importance of screening and aligned hygiene measures in patients admitted from refugee accommodations. It is hard to estimate the whether the REF population in the UHF setting is representative of the overall refugee population in Germany. However, a study also conducted in Frankfurt am Main but in unaccompanied refugee minors ( 18 years- old) in refugee centres also found a high prevalence of ESBL-producing Enterobacteriaceae (35\%) even though lower than that in our study [17].

One limitation of our study may be the pre-selection of NREF. As mentioned above, this group consists of patients admitted to ICUs and IMCs: considering that they are critically ill, possible prior antibiotic treatment might have resulted in increased prevalence of MDRO in the NREF group used for comparison. This might lead to an overestimation of the MDRO prevalence in our NREF group and thus to an underestimation of the difference in MDRO prevalences between REF and NREF patients.

Unfortunately, information regarding refugees' itineraries were not available due to missing records in the patient files and the language barrier on hospital admission. Such information, however, would help to better understand the origin and transmission routes of MDROs. For example refugees might have acquired a particular MDRO during their transit through a country with high prevalence. Future investigations on clonal relatedness and comparisons with major endemic clones should allow to analyse the spread of MDRO in connection with the movements of refugees.

At UHF, all REF are screened for MDRO and pre-emptively isolated on the day of admission. In case of negative screening results, REF are released from isolation. In case of positive MDR GNB and/or MRSA results, REF remain in isolation during their entire stay. Since June 2015, this procedure has been implemented and guarantee best medical practice for every individual patient at UHF, independently of their country of origin.
Acknowledgements

Authors declare that this report is exclusively based on epidemiological findings and is not influenced by any political opinion. Authors furthermore confirm that all patients are treated equally and in conditions of best medical care at UHF, regardless of their origin. Stephan Göttig and Volkhard A. J. Kempf were supported by a grant from the Deutsche Forschungsgemeinschaft (DFG-research unit 2251).

\section{Conflicts of interest}

The authors declare that they have no competing interests.

\section{Authors' contributions}

CR: compiling and interpretation of the data, manuscript writing. VK: interpretation of the data, manuscript writing. SG, MH, TW: generation and interpretation of the data, manuscript writing. FOR: manuscript review. CB: compiling and interpretation of the data, manuscript writing. All authors read and approved the final manuscript.

\section{References}

1. Bundesamt für Migration und Flüchtlinge. Aktuelle Zahlen zu Asyl. Ausgabe November 2015. [Accessed 21 Dec 2015]. German. Available from: http://www.soziales.bremen.de/ sixcms/media.php/13/statistik-anlage-teil-4-aktuelle-zahlenzu-asyl.pdf

2. Hassing RJ, Alsma J, Arcilla MS, van Genderen PJ, Stricker $\mathrm{BH}$, Verbon A. International travel and acquisition of multidrug-resistant Enterobacteriaceae: a systematic review.Euro Surveill. 2015;20(47). DOI: 10.2807/1560-7917. ES.2015.20.47.30074 PMID: 26625301

3. Josseaume J, Verner L, Brady WJ, Duchateau FX. Multidrug resistant bacteria among patients treated in foreign hospitals: management considerations during medical repatriation.J Travel Med. 2013;20(1):22-8.DOI: 10.1111/j.17088305.2012.00668.x PMID: 23279227

4. Aqel AA, Alzoubi HM, Vickers A, Pichon B, Kearns AM. Molecular epidemiology of nasal isolates of methicillinresistant Staphylococcus aureus from Jordan.J Infect Public Health. 2015;8(1):90-7.DOI: 10.1016/j.jiph.2014.05.007 PMID: 25002017

5. Teicher CL, Ronat JB, Fakhri RM, Basel M, Labar AS, Herard $P$, et al. Antimicrobial drug-resistant bacteria isolated from Syrian war-injured patients, August 2011-March 2013. Emerg Infect Dis. 2014;20(11):1949-51.DOI: 10.3201/eid2011.140835 PMID: 25340505

6. Doyle D, Peirano G, Lascols C, Lloyd T, Church DL, Pitout JD. Laboratory detection of Enterobacteriaceae that produce carbapenemases.J Clin Microbiol. 2012;50(12):3877-80.DOI: 10.1128/JCM.02117-12 PMID: 22993175

7. Higgins PG, Dammhayn C, Hackel M, Seifert H. Global spread of carbapenem-resistant Acinetobacter baumannii.J Antimicrob Chemother. 2010;65(2):233-8.DOI: 10.1093/jac/dkp428 PMID: 19996144

8. Göttig S, Gruber TM, Stecher B, Wichelhaus TA, Kempf VA. In vivo horizontal gene transfer of the carbapenemase OXA-48 during a nosocomial outbreak.Clin Infect Dis. 2015;60(12):1808-15.DOI: 10.1093/cid/civ191 PMID: 25759432

9. Harmsen D, Claus H, Witte W, Rothgänger J, Claus H, Turnwald $\mathrm{D}$, et al. Typing of methicillin-resistant Staphylococcus aureus in a university hospital setting by using novel software for spa repeat determination and database management. J Clin Microbiol. 2003;41(12):5442-8.DOI: 10.1128/JCM.41.12.54425448.2003 PMID: 14662923

10. University of Münster. Konfidenzintervall für binomialverteilte Anteilswerte. [Accessed 21 Dec 2015]. Available from: http:// campus.uni-muenster.de/fileadmin/einrichtung/ibkf/lehre/ skripte/biomathe/bio/konf1.html

11. MOSAR WP $2, W_{3}$ and WP5 study groups,Papagiannitsis CC, Izdebski R, Baraniak A, Fiett J, Herda M, Hrabák J, et al. . Survey of metallo- $\beta$-lactamase-producing Enterobacteriaceae colonizing patients in European ICUs and rehabilitation units, 2008-11.J Antimicrob Chemother. 2015;70(7):1981-8. DOI: 10.1093/jac/dkv055 PMID: 25759034 
12. Izdebski R, Bojarska K, Baraniak A, Literacka E, Herda M, Żabicka D, et al. NDM-1- or OXA-48-producing

Enterobacteriaceae colonising Polish tourists following a terrorist attack in Tunis, March 2015. Euro Surveill. 2015;20(23):21150.DOI: 10.2807/1560-7917.ES2015.20.23.21150 PMID: 26084313

13. Heydari F, Mammina C, Koksal F. NDM-1-producing Acinetobacter baumannii ST85 now in Turkey, including one isolate from a Syrian refugee.J Med Microbiol. 2015;64(9):10279.DOI: $10.1099 / j m m .0 .000132$ PMID: 26296677

14. Eurosafety Health-Net. Interreg Deutschland - Nederland. MRSA Typisierungen 2008-2011. [MRSA typing 2008-2011]. [Accessed 21 Dec 2015]. German. Available from: http://www. eursafety.eu/pdf/spa_Typisierungen_EurSafety_ shortform.pdf

15. Empfehlung der Kommission für Krankenhaushygiene und Infektionsprävention (KRINKO) beim Robert Koch-Institut: Prävention und Kontrolle von MRSA in medizinischen und pflegerischen Einrichtungen. [Hygiene measures for infection or colonization with multidrug-resistant gram-negative bacilli. Commission recommendation for hospital hygiene and infection prevention (KRINKO at the Robert Koch Institute RKI): Prevention and control of MRSA in medical and nursing facilities]. Bundesgesundheitsblatt Gesundheitsforschung Gesundheitsschutz. 2014;57(6):696-732.

16. Hygienemaßnahmen bei Infektionen oder Besiedlung mit multiresistenten gramnegativen Stäbchen. Empfehlung der Kommission für Kranken-haushygiene und

Infektionsprävention (KRINKO) beim Robert Koch-Institut (RKI). [Hygiene measures for infection or colonization with multidrug. resistant gram-negative bacilli. Commission recommendation for hospital hygiene and infection prevention ) (KRINKO at the Robert Koch Institute RKI)]. Bundesgesundheitsblatt Gesundheitsforschung Gesundheitsschutz. 2012;55(10):131154.DOI: $10.1007 /$ s00103-012-1549-5 PMID: 23011096

17. Heudorf U, Krackhardt B, Karathana M, Kleinkauf N, Zinn C. Multidrug-resistant bacteria in unaccompanied refugee minors arriving in Frankfurt am Main, Germany, October to November 2015. Euro Surveill. 2016;21(2):30109.

\section{License and copyright}

This is an open-access article distributed under the terms of the Creative Commons Attribution (CC BY 4.0) Licence. You may share and adapt the material, but must give appropriate credit to the source, provide a link to the licence, and indicate if changes were made.

This article is copyright of the authors, 2016. 